\title{
Organocatalytic cascade aza-Michael/hemiacetal reaction between disubstituted hydrazines and $\alpha, \beta$-unsaturated aldehydes: Highly diastereo- and enantioselective synthesis of pyrazolidine derivatives
}

\author{
Zhi-Cong Geng, Jian Chen, Ning Li, Xiao-Fei Huang, Yong Zhang, \\ Ya-Wen Zhang ${ }^{*}$ and Xing-Wang Wang ${ }^{*}$
}

Full Research Paper

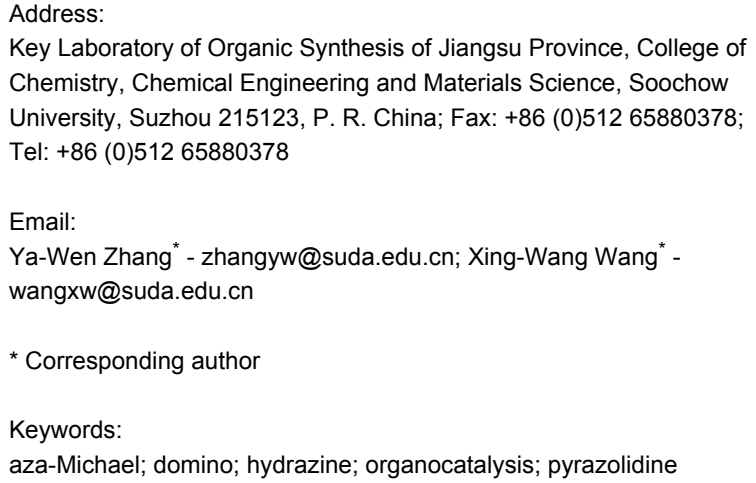

Key Laboratory of Organic Synthesis of Jiangsu Province, College of Chemistry, Chemical Engineering and Materials Science, Soochow University, Suzhou 215123, P. R. China; Fax: +86 (0)512 65880378; Tel: +86 (0)512 65880378

Email:

Ya-Wen Zhang* - zhangyw@suda.edu.cn; Xing-Wang Wang* wangxw@suda.edu.cn

* Corresponding author

Keywords:

aza-Michael; domino; hydrazine; organocatalysis; pyrazolidine

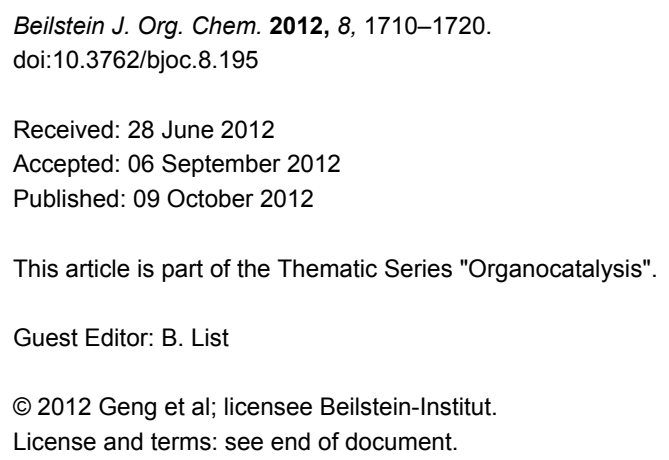

\begin{abstract}
The catalytic synthesis of nitrogen-containing heterocycles is of great importance to medicinal and synthetic chemists, and also a challenge for modern chemical methodology. In this paper, we report the synthesis of pyrazolidine derivatives through a domino aza-Michael/hemiacetal sequence with chiral or achiral secondary amines as organocatalysts. Thus, a series of achiral pyrazolidine derivatives were obtained with good yields (up to 90\%) and high diastereoselectivities (>20:1) with pyrrolidine as an organocatalyst, and enantioenriched pyrazolidines are also achieved with good results (up to 86\% yield, $>10 / 1$ regioselectivity, $>20: 1 \mathrm{dr}$, $99 \%$ ee) in the presence of $(S)$-diphenylprolinol trimethylsilyl ether catalyst.
\end{abstract}

\section{Introduction}

Pyrazolidines are privileged and valuable heterocyclic compounds, which are of great importance in biological and medicinal chemistry (Figure 1) [1-5]. Besides, pyrazolidines are also important synthetic intermediates in organic chemistry. For instance, the $\mathrm{N}-\mathrm{N}$ bond of pyrazolidines can be cleaved under reductive conditions to afford useful 1,3-diamines [6,7], and moreover, pyrazolidines can also be oxidized to afford pyrazolines [8-12] and pyrazoles [13-15]. The pyrazolidine structural unit is commonly constructed by $[3+2]$ cycloaddition reactions using hydrazones [16-23] or azomethine amines [24-27] as dipoles. Recently, the Ma group and Toste et al. have reported efficient methods for the synthesis of pyrazolidine derivatives 


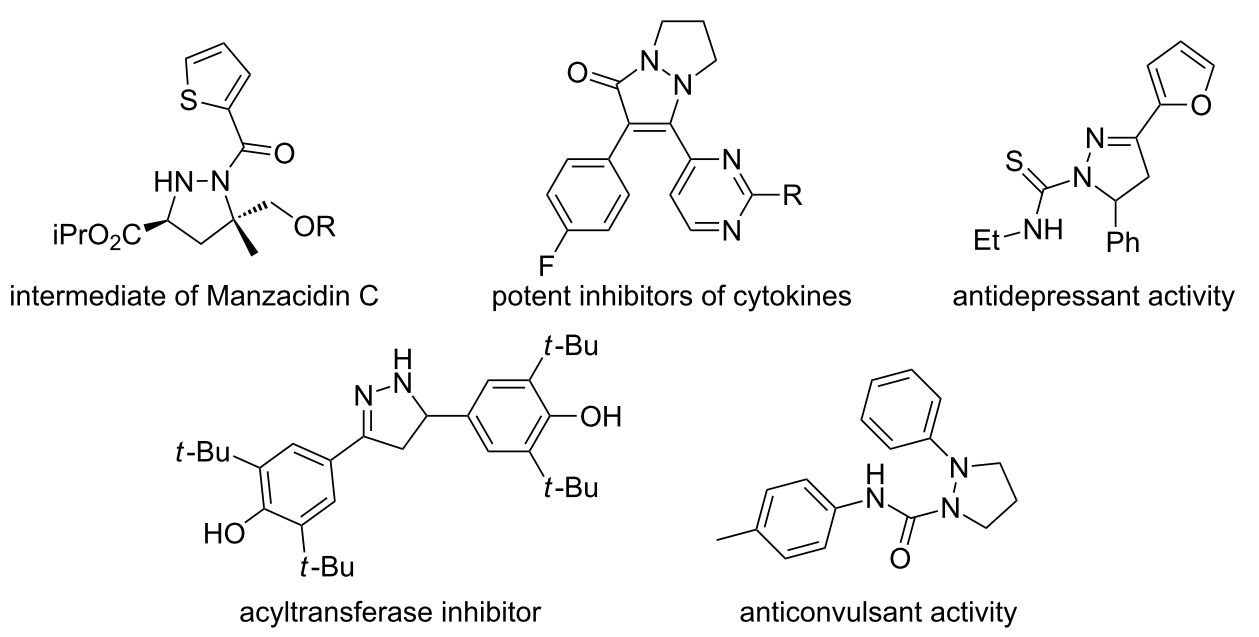

Figure 1: Important heterocycles containing pyrazolidine or pyrazoline structures.

by metal-catalyzed aminations of allenes [28-32]. Meanwhile, Lewis acid catalyzed carboamination reactions have also been reported as efficient methods for the synthesis of pyrazolidine derivatives by Wolfe et al. [33].

In the past decade, the research area of organocatalysis has grown rapidly and become a third brand of catalysis besides the well-established biocatalysis and metal catalysis [34-44]. Particularly, organocatalytic domino/cascade reactions have come into focus and become a powerful synthetic approach that allows the construction of structurally diverse and complex molecules, minimizes the number of manual operations, and saves time, effort, and production costs [45-47]. Thus, many nitrogen-containing heterocyclic compounds have been efficiently generated by means of organocatalytic domino reactions [48-69].

In 2009 and 2010, List et al. and the Brière group both reported, separately, the enantioselective synthesis of 2-pyrazolines starting from $\alpha, \beta$-unsaturated ketones and phenylhydrazine or $N$-tert-butyloxycarbonylhydrazine in the presence of a chiral Brønsted acid or a phase-transfer catalyst [70,71]. Compared with monosubstituted hydrazines in organocatalytic asymmetric synthesis, disubstituted hydrazines were also explored by several groups [72,73]. In 2007, Jørgensen et al. reported that the organocatalyzed asymmetric aza-Michael addition of hydrazones to cyclic enones had been achieved in good yield and stereoselectivity [74]. In 2011, the Deng group developed a highly enantioselective organocatalytic synthesis of 2-pyrazolines using disubstituted hydrazines through an asymmetric conjugate addition followed by a deprotection-cyclization sequence [75]. Due to the importance of pyrazolidine derivatives in both organic and medicinal chemistry, we have become interested in developing an efficient stereoselective cascade reaction for the synthesis of the pyrazolidine compounds through organocatalysis. In this paper, we present a convenient access to racemic and enantioenriched 5-hydroxypyrazolidines through a domino aza-Michael/hemiacetal organocatalytic sequence of disubstituted hydrazines to $\alpha, \beta$-unsaturated aldehydes. While proceeding with the submission of our results, we noticed that a related excellent work has been reported by Vicario and co-workers [76]. When comparing Vicario's work with this manuscript, both works are complementary in scope since Vicario's work makes use of unsaturated aldehydes containing only linear alkyl chains, whereas our work provides better results when unsaturated aldehydes bearing an aromatic moiety are employed.

\section{Results and Discussion}

First, the cascade aza-Michael/hemiacetal reactions between disubstituted hydrazines 2a-c and 4-nitrocinnamaldehyde (3a) were investigated in the presence of several common secondary amines 1a-f as organocatalysts in chloroform. Pyrrolidine (1c) turned out to be an effective catalyst and di-tert-butyl hydrazine-1,2-dicarboxylate (2c) was a potent donor (see Table $\mathrm{S} 1$ in the Supporting Information File 1). When di-tert-butyl hydrazine-1,2-dicarboxylate (2c) was used as the donor and $20 \mathrm{~mol} \%$ pyrrolidine (1c) as the catalyst, 5-hydroxypyrazolidine 4 a could be obtained in $68 \%$ yield with over $20: 1 \mathrm{dr}$ after five days (Table 1, entry 1). Thus, the tandem aza-Michael/ hemiacetal reaction between di-tert-butyl hydrazine-1,2-dicarboxylate (2c) and 4-nitrocinnamaldehyde (3a) was chosen as the model reaction to further optimize the reaction conditions. The catalytic results were summarized in Table 1. In order to improve the yield, a variety of common solvents were screened (Table 1, entries 2-6). Dichloromethane was finally found to be 
Table 1: Secondary amine catalyzed cascade aza-Michael/hemiacetal reaction.

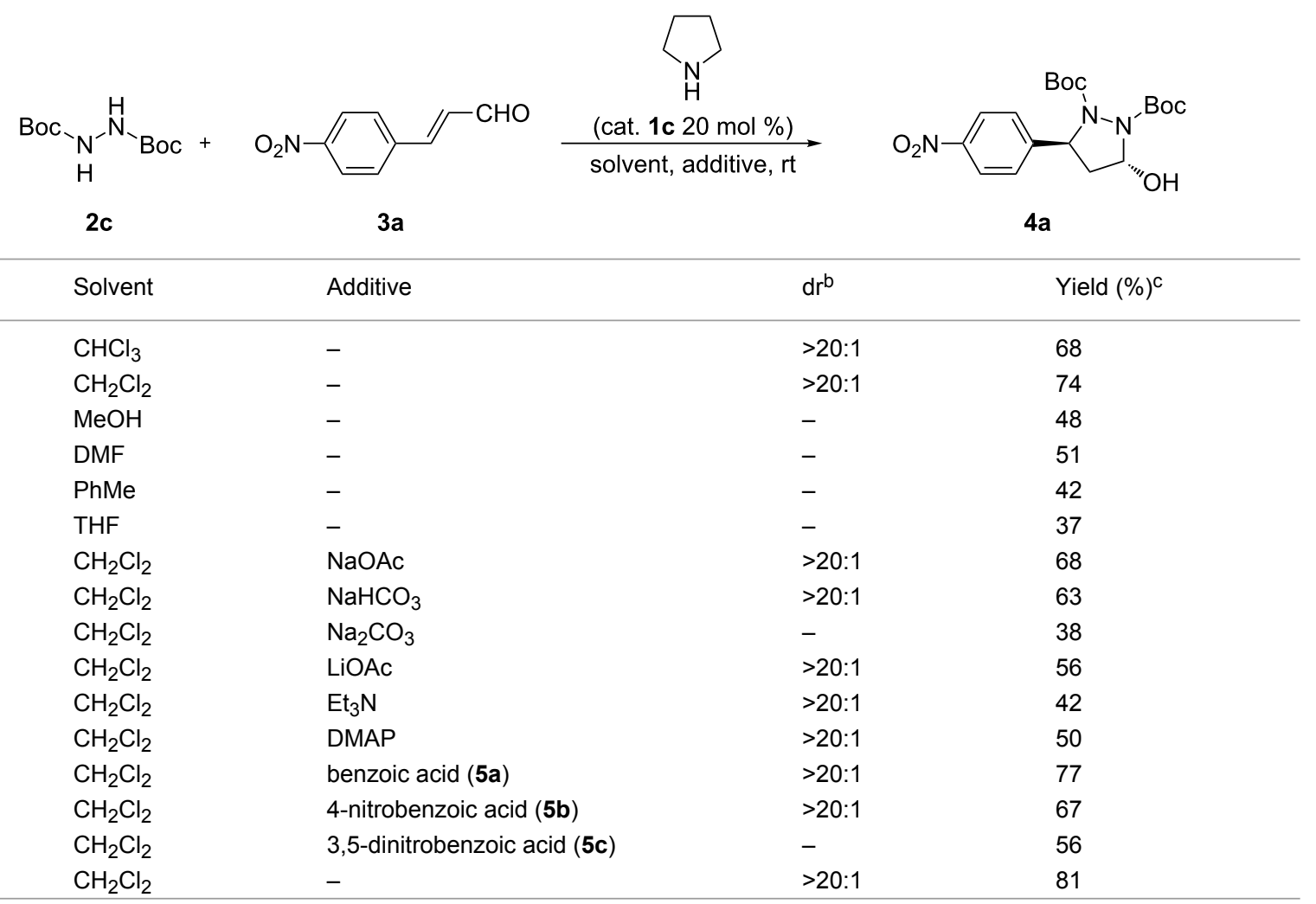

aThe reaction was run with $2 \mathrm{c}(0.3 \mathrm{mmol}), 3 \mathrm{a}(0.25 \mathrm{mmol}), 1 \mathrm{c}(0.05 \mathrm{mmol})$ and the specified additive $(0.05 \mathrm{mmol})$ in the given solvent $(0.5 \mathrm{~mL})$ at room temperature for $5 \mathrm{~d}$. ${ }^{\mathrm{b}}$ Determined by ${ }^{1} \mathrm{H}$ NMR. ${ }^{C}$ Isolated yield. ${ }^{\mathrm{d}}$ The molar ratio of $2 \mathrm{c} / 3 \mathbf{a}$ is $2.0: 1$.

the best medium for this reaction (74\% yield with excellent diastereoselectivity was achieved, Table 1 , entry 2 ). Subsequently, the effects of some basic/and acidic additives were examined. Inorganic bases seemed to be ineffective for the further improvement of the yields (Table 1, entries 7-10). Soluble organic bases were also tested and failed to increase the yields (Table 1, entries 11 and 12). When benzoic acid (5a) was used as an additive, the yield was slightly improved to $77 \%$ (Table 1 , entry 13). With the increase of the acidity, the yield was noticeably decreased (Table 1, entry 13 versus entries 14 and 15). Finally, when increasing the amount of di-tert-butyl hydrazine1,2-dicarboxylate (2c) to 2 equiv, the desired product $4 \mathbf{a}$ was obtained in $81 \%$ yield without any additive (Table 1, entry 16 ).

Having established the optimized reaction conditions, we investigated the scope of substrates for the cascade aza$\mathrm{Michael} /$ hemiacetal reaction with pyrrolidine (1c, $20 \mathrm{~mol} \%$ ) as the catalyst, without any additives, in methylene chloride (Table 2). We found that the nature of the substituents on the phenyl group of $\alpha, \beta$-unsaturated aldehydes dramatically affected the reactivity. For example, with disubstituted hydrazine $2 \mathbf{c}$ as the donor, the presence of a stronger electron- deficient substituent $\left(-\mathrm{NO}_{2},-\mathrm{CN}\right)$ on the phenyl ring of the $\alpha, \beta$ unsaturated aldehydes $\mathbf{3 a}, \mathbf{3 b}$ and $\mathbf{3 c}$ promoted the cascade azaMichael/hemiacetal reaction readily to provide the desired products in good yields $(75-81 \%$, Table 2 , entries $1-3)$. The presence of less-electron-deficient substituents $(-\mathrm{Cl}$ and $-\mathrm{Br})$ on the phenyl ring of the $\alpha, \beta$-unsaturated aldehydes, such as 4-chloroor 4-bromocinnamaldehyde derivatives $\mathbf{3 d}$ and $\mathbf{3 e}$, afforded the corresponding products in moderate yields (64 and 74\%) even when 5 equiv of disubstituted hydrazine 2c was used (Table 2, entries 4 and 5). When cinnamaldehyde derivatives $\mathbf{3 f}$ and $\mathbf{3 g}$, bearing electron-donating substituents (-Me, -OMe) on phenyl rings, were used as the substrate, the reactions became very sluggish (Table 2, entries 6 and 7). On the other hand, more symmetric and asymmetric hydrazine derivatives $\mathbf{2 d}-\mathbf{h}$ were synthesized and investigated for the tandem aza-Michael/hemiacetal reaction. Generally, all the reactions between $\mathbf{2 d - h}$ and $\alpha, \beta$-unsaturated aldehydes $\mathbf{3 a}$ and $\mathbf{3 b}$ proceeded smoothly with sequential catalytic actions of $\mathbf{1 c}$, affording the corresponding desired products $\mathbf{4 h}-\mathbf{o}$ in moderate to good yields (Table 2, entries 8-11 and 13-16). Notably, the reaction between 2e and 4-methoxycinnamaldehyde (3f) afforded the desired product in $52 \%$ yield (Table 2 , entry 12 ). For the asymmetric disubstituted 
Table 2: Substrate scope for the cascade aza-Michael/hemiacetal reactions between 2 and $\alpha, \beta$-unsaturated aldehydes 3.<smiles>[R]C=CC=O</smiles>

2c: $R^{1}=R^{2}=$ Boc; $2 d: R^{1}=R^{2}=$ COOiPr

2e: $R^{1}=R^{2}=C b z ; 2 f: R^{1}=R^{2}=$ COOEt

2g: $\mathbf{R}^{1}=$ Boc, $\mathbf{R}^{2}=\mathrm{Ph} ; \mathbf{2 h}: \mathrm{R}^{1}=\mathrm{Boc}, \mathrm{R}^{2}=p-\mathrm{CIPh}$

\begin{tabular}{|c|c|c|c|c|}
\hline Entry $^{a}$ & Donor & $\mathrm{R}^{3}$ & $d r^{b}$ & Yield $(\%)^{c}$ \\
\hline 1 & 2c & $4-\mathrm{NO}_{2} \mathrm{C}_{6} \mathrm{H}_{4}(\mathbf{3 a})^{\mathrm{d}}$ & $>20: 1$ & $4 a / 81$ \\
\hline 2 & 2c & $3-\mathrm{NO}_{2} \mathrm{C}_{6} \mathrm{H}_{4}(3 \mathrm{~b})^{\mathrm{d}}$ & $>20: 1$ & $4 b / 78$ \\
\hline 3 & $2 c$ & $4-\mathrm{CNC}_{6} \mathrm{H}_{4}(3 \mathrm{c})^{\mathrm{d}}$ & $>20: 1$ & $4 c / 75$ \\
\hline 4 & 2c & $4-\mathrm{ClC}_{6} \mathrm{H}_{4}(3 \mathrm{~d})^{\mathrm{e}}$ & $>20: 1$ & $4 d / 64$ \\
\hline 5 & 2c & $4-\mathrm{BrC}_{6} \mathrm{H}_{4}(3 e)^{\mathrm{e}}$ & $>20: 1$ & $4 e / 74$ \\
\hline 6 & 2c & $4-\mathrm{MeOC}_{6} \mathrm{H}_{4}(\mathbf{3 f})^{\mathrm{d}}$ & - & $4 f /<5$ \\
\hline 7 & 2c & $4-\mathrm{MeC}_{6} \mathrm{H}_{4}(\mathbf{3 g})^{\mathrm{d}}$ & - & $4 \mathbf{g} /<5$ \\
\hline 8 & $2 d$ & $4-\mathrm{NO}_{2} \mathrm{C}_{6} \mathrm{H}_{4}(\mathbf{3 a})^{\mathrm{d}}$ & $>20: 1$ & $4 \mathrm{~h} / 86$ \\
\hline 9 & 2d & $3-\mathrm{NO}_{2} \mathrm{C}_{6} \mathrm{H}_{4}(3 \mathbf{b})^{\mathrm{d}}$ & $>20: 1$ & $4 i / 82$ \\
\hline 10 & $2 e$ & $4-\mathrm{NO}_{2} \mathrm{C}_{6} \mathrm{H}_{4}(\mathbf{3 a})^{\mathrm{d}}$ & $>20: 1$ & $4 \mathbf{j} / 90$ \\
\hline 11 & $2 e$ & $3-\mathrm{NO}_{2} \mathrm{C}_{6} \mathrm{H}_{4}(3 b)^{d}$ & $>20: 1$ & $4 \mathrm{k} / 76$ \\
\hline 12 & $2 e$ & $4-\mathrm{MeOC}_{6} \mathrm{H}_{4}(\mathbf{3 f})^{\mathrm{d}}$ & $>20: 1$ & $41 / 52$ \\
\hline 13 & $2 f$ & $4-\mathrm{NO}_{2} \mathrm{C}_{6} \mathrm{H}_{4}(\mathbf{3 a})^{\mathrm{d}}$ & $>20: 1$ & $4 \mathrm{~m} / 77$ \\
\hline 14 & $2 g$ & $4-\mathrm{NO}_{2} \mathrm{C}_{6} \mathrm{H}_{4}(3 \mathrm{a})^{\mathrm{f}}$ & $>20: 1$ & $4 n / 20(43)$ \\
\hline 15 & $2 g$ & $4-\mathrm{NO}_{2} \mathrm{C}_{6} \mathrm{H}_{4}(\mathbf{3 a})^{\mathrm{f}, \mathrm{g}}$ & $>20: 1$ & $4 n / 72(<5)$ \\
\hline 16 & $2 \mathrm{~h}$ & $3-\mathrm{NO}_{2} \mathrm{C}_{6} \mathrm{H}_{4}(3 b)^{\mathrm{f}, \mathrm{g}}$ & $>20: 1$ & $40 / 66(<5)$ \\
\hline
\end{tabular}

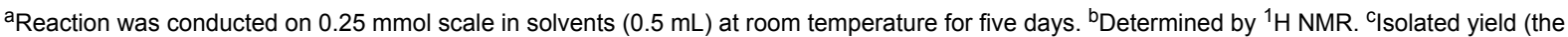
data in parentheses is related to the isolated yield of the regioselective product). ${ }^{\mathrm{d}}$ The ratio of $\mathbf{2 / 3}$ is $2.0: 1 .{ }^{\mathrm{e}}$ The ratio of $\mathbf{2} / \mathbf{3}$ is $5.0: 1$. ${ }^{\mathrm{f}}$ The ratio of $\mathbf{2 / 3}$ is 1.2:1. ${ }^{\mathrm{g}} 100 \mathrm{~mol} \%$ of pyrrolidine was used at $\mathrm{rt}$ for $12 \mathrm{~h}$.

hydrazines $\mathbf{2} \mathbf{g}$ and $\mathbf{2 h}$ as substrates, regioselective results could be observed (Table 2, entry 14). However, with increasing catalyst loading from catalytic to stoichiometric amounts, the corresponding cascade reactions could provide the major products in 72 and 66\% yields (Table 2, entries 15 and 16). In all the reactions, high diastereoselectivity could be obtained ( $>20: 1$ dr). Finally, we were able to obtain single crystals of compounds $4 \mathbf{a}$ and $\mathbf{4 n}$, which allowed for an unambiguous assignment of the trans configuration of $\mathrm{C} 3$ and $\mathrm{C} 5$ by X-ray crystallographic analysis (Figure 2 and Figure 3).

Then, we turned our attention to the development of the asymmetric version of the cascade aza-Michael/hemiacetal reaction. Initially, a series of readily available chiral organocatalysts 1g-o were chosen and investigated for the domino azaMichael/hemiacetal reaction of disubstituted hydrazine $2 \mathbf{c}$ and 4-nitrocinnamaldehyde (3a) under catalytic loading of $20 \mathrm{~mol} \%$ in $\mathrm{CH}_{2} \mathrm{Cl}_{2}$ at room temperature. The screening results are summarized in Table 3. (S)-Proline derivatives $\mathbf{1 g - h}, \mathbf{1 k}, \mathbf{1 l}$

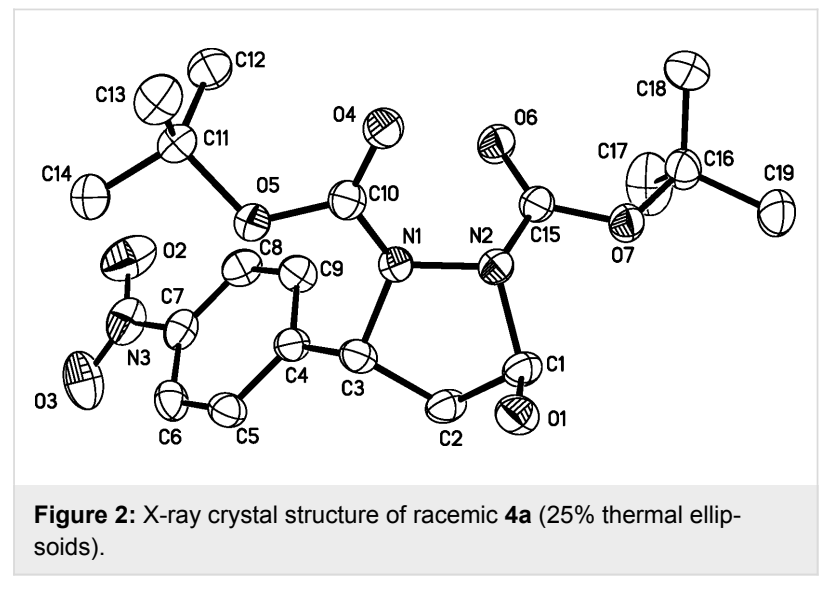

were found to be ineffective for the reaction, because they afford only trace products after one day (Table 3, entries 1, 2, 5 and 6). Although a moderate yield was obtained with organocatalyst 1i bearing a sulfone functional group, the stereochemical induction was very poor (Table 3 , entry 3 ). MacMillan's cata- 


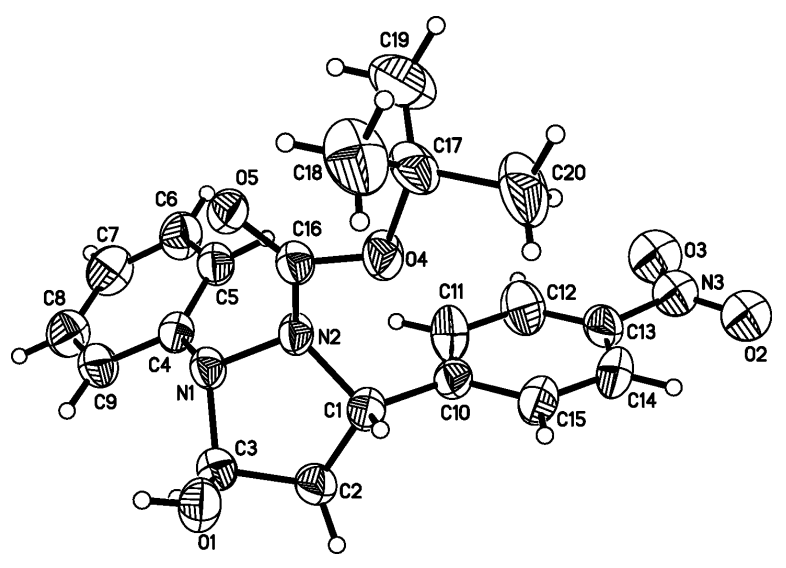

Figure 3: X-ray crystal structure of racemic 4n (25\% thermal ellipsoids). lyst $\mathbf{1} \mathbf{j}$ was proven to be inefficient for this transformation as only $13 \%$ ee was obtained (Table 3 , entry 4 ). Subsequently, three diarylprolinol silyl ether catalysts $\mathbf{1} \mathbf{m}-\mathbf{o}$ were investigated for this tandem reaction [77-79]. Gratifyingly, $82 \%$ ee was achieved when $\mathbf{1} \mathbf{m}$ was used as the catalyst. For catalysts $\mathbf{1 n}$ and 1o, slightly higher yields could be obtained, but the enantioselectivities became lower (Table 3, entry 7 versus entries 8 and 9). Relatively speaking, $(S)$-diphenylprolinol trimethylsilyl ether $1 \mathbf{m}$ turned out to be the optimal catalyst in terms of both enantioselectivity and reactivity.

Having identified the readily available catalyst $\mathbf{1} \mathbf{m}$ as the optimal catalyst for the tandem aza-Michael/hemiacetal reaction of $\mathbf{2} \mathbf{c}$ and $\mathbf{3 a}$, we summarize the results for the optimization of the other reaction parameters, including reaction solvents and additives, in Table 4 . When the reaction was carried out in a protonic solvent, i.e., methanol, at room temperature for two days, the desired product was furnished in

Table 3: Chiral-amine-catalyzed cascade aza-Michael/hemiacetal reaction of $2 \mathrm{c}$ with $3 \mathbf{a}$.<smiles>CC(C)(C)OC(=O)NNC(=O)OC(=O)OC(=O)OC(C)(C)C</smiles><smiles>C1CNC(c2nnn[nH]2)C1</smiles>

$1 \mathrm{~g}$<smiles>S=C(NCC1CCCN1)Nc1ccccc1</smiles>

$1 \mathrm{~h}$<smiles>O=S(=O)(CC1CCCN1)Oc1ccccc1</smiles>

$1 \mathrm{i}$<smiles>CN1C(=O)C(Cc2ccccc2)NC1(C)Cl</smiles>

$1 \mathrm{j}$<smiles>OC(c1ccccc1)(c1ccccc1)C1CCCN1</smiles>

$1 \mathrm{k}$<smiles>CCOC(c1ccccc1)(c1ccccc1)C1CCCN1</smiles><smiles>C[AsH3]OC(c1ccccc1)(c1ccccc1)C1CCCN1</smiles><smiles>CC(C)(C)OC(c1ccccc1)(c1ccccc1)C1CCCN1</smiles><smiles>COC(Br)(Br)C1CCCN1</smiles>
$\mathrm{Ar}=3,5-\left(\mathrm{CH}_{3}\right)_{2} \mathrm{Ph}$

11 $1 \mathrm{~m}$

$1 n$ 10

\begin{tabular}{lllll}
\hline Entry $^{\mathrm{a}}$ & $\mathbf{R}$ & Time $(\mathrm{d})$ & Yield $(\%)^{\mathrm{b}}$ & ee (\%) \\
\hline 1 & $\mathbf{1 g}$ & 1 & $<10$ & n.d. \\
2 & $\mathbf{1}$ & 1 & $<5$ & n.d. \\
3 & $\mathbf{1 i}$ & 1 & 48 & 5 \\
4 & $\mathbf{1 j}$ & 1 & 21 & 13 \\
5 & $\mathbf{1 k}$ & 1 & $<10$ & n.d. \\
6 & $\mathbf{1}$ & 1 & $<5$ & n.d. \\
7 & $\mathbf{1}$ & 1 & 86 & 82 \\
8 & $\mathbf{1 n}$ & 1 & 89 & $(-) 79^{d}$ \\
9 & $\mathbf{1 0}$ & 1 & 87 & 76 \\
\hline
\end{tabular}

aThe reaction was run with $2 \mathrm{c}(0.5 \mathrm{mmol}), 3 \mathrm{a}(0.25 \mathrm{mmol})$, and $1(0.05 \mathrm{mmol})$ in $\mathrm{CH}_{2} \mathrm{Cl}_{2}(0.5 \mathrm{~mL})$ at room temperature. ${ }^{\mathrm{b}}$ lsolated yield. ${ }^{\mathrm{C}}$ Determined by HPLC analysis on a chiral stationary phase $\left(\right.$ Chiralcel OD-H), $>20: 1 \mathrm{dr}$. ${ }^{\mathrm{d}}$ Opposite enantiomer of the product formed. $\mathrm{n} . \mathrm{d}$. $=$ not determined. 
Table 4: Optimization of the reaction of $2 \mathrm{c}$ and $3 \mathrm{a}$ catalyzed by chiral amine $1 \mathrm{~m}$.

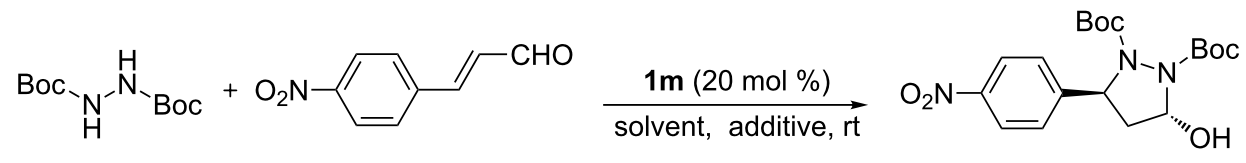

2c<smiles>O=C(O)c1ccc([N+](=O)[O-])cc1</smiles>

$5 \mathbf{b}$<smiles>O=C(O)[C](O)c1ccccc1</smiles>

$5 g$
$3 a$<smiles>O=C(O)[C@@H]1CCCN1</smiles>

5d<smiles>O=C(O)[C@H](O)c1ccccc1</smiles>

$5 h$<smiles>O=C(O)C(NC(C(=O)O)c1ccccc1)c1ccccc1</smiles>

$5 e$<smiles>O=P1(O)Oc2ccc3ccccc3c2-c2c(ccc3ccccc23)O1</smiles>

$5 i$
$4 a$<smiles>CC(C)(C)O[Pb](=O)[C@H](C(=O)O)c1ccccc1</smiles>

$5 f$<smiles>CC1(C)COP(=O)(O)O[C@H]1c1ccccc1Cl</smiles>

5j

\begin{tabular}{|c|c|c|c|c|c|}
\hline Entry $^{a}$ & Additive & Solvent & Time $(d)$ & Yield $(\%)^{b}$ & ee $(\%)^{c}$ \\
\hline 1 & - & $\mathrm{MeOH}$ & 2 & 56 & 22 \\
\hline 2 & - & $\mathrm{CHCl}_{3}$ & 1 & 84 & 75 \\
\hline 3 & - & $\mathrm{CHCl}_{2}$ & 1 & 86 & 82 \\
\hline 4 & - & THF & 2 & 51 & 92 \\
\hline 5 & - & PhMe & 2 & 72 & 92 \\
\hline 6 & - & PhMe & 4 & 80 & 92 \\
\hline 7 & $5 b$ & PhMe & 4 & 27 & 93 \\
\hline 8 & $5 d$ & PhMe & 4 & 56 & 94 \\
\hline 9 & $5 e$ & PhMe & 4 & 48 & 92 \\
\hline 10 & $5 f$ & PhMe & 4 & 45 & 92 \\
\hline 11 & $5 g$ & PhMe & 4 & 51 & 94 \\
\hline 12 & $5 h$ & PhMe & 4 & 20 & 94 \\
\hline 13 & $5 i$ & PhMe & 4 & 38 & 94 \\
\hline 14 & $5 j$ & PhMe & 4 & 53 & 95 \\
\hline 15 & LiOAC & PhMe & 4 & 79 & 93 \\
\hline 16 & DMAP & PhMe & 4 & 83 & 87 \\
\hline 17 & DABCO & PhMe & 4 & 79 & 89 \\
\hline 18 & $\mathrm{Et}_{3} \mathrm{~N}$ & PhMe & 4 & 83 & 87 \\
\hline 19 & TMEDA & PhMe & 4 & 81 & 88 \\
\hline 20 & DBU & PhMe & 4 & 58 & 11 \\
\hline
\end{tabular}

aThe reaction was run with $2 \mathrm{c}(0.5 \mathrm{mmol}), 3 \mathrm{a}(0.25 \mathrm{mmol}), 1 \mathrm{~m}(0.05 \mathrm{mmol})$ and the specified additive $(0.05 \mathrm{mmol})$ in the given solvent $(0.5 \mathrm{~mL})$ at room temperature. ${ }^{b}$ Isolated yield. 'Determined by HPLC analysis on a chiral stationary phase (Chiralcel OD-H), >20:1 dr.

$56 \%$ yield with only $22 \%$ ee (Table 4 , entry 1 ). After screening several aprotic solvents for this reaction, we were pleased to find that the enantioselectivity of the desired product was improved to $92 \%$ ee with toluene or THF as solvent after two days (Table 4, entries 4 and 5). Considering both yield and enantioselectivity, toluene was the optimal reaction medium (Table 4, entry 5). When the time was prolonged to four days, the yield of the product was increased to $80 \%$ and the enantioselectivity was retained (Table 4, entry 6). Thereafter, several Brønsted acids $\mathbf{5 b}, \mathbf{5 d}-\mathbf{j}$ were tested as additives for this transformation. Although enantioselectivity was somewhat improved from 92 to $95 \%$ ee, the reactivity dramatically decreased as evidenced by the prolonged reaction time and lower yields (Table 4, entry 6 versus entries 7-14). It seemed that the present catalytic system could be inhibited by acidic additives. Therefore, we considered whether the reaction could be accelerated by basic additives without loss of enantioselectivity and reactivity. Subsequently, several common inorganic and organic bases were 
investigated [80-83]. Unfortunately, the catalytic results showed that with LiOAc, DMAP, DABCO, $\mathrm{Et}_{3} \mathrm{~N}$, TMEDA as additives, the yield and enantioselectivity were only marginally influenced (Table 4, entries 15-19). When DBU was used as an additive, only $11 \%$ ee was obtained with moderate yield (Table 4, entry 20). Thus, $1 \mathbf{m}(20 \mathrm{~mol} \%)$ as the catalyst and toluene as the reaction medium without any additive at room temperature proved to be the optimal reaction conditions for the asymmetric cascade aza-Michael/hemiacetal reaction.

With the optimized reaction conditions in hand, the substrate scope of the organocatalyzed asymmetric domino aza-Michael/ hemiacetal sequence was subsequently explored. Firstly, with symmetric di-tert-butyl hydrazine-1,2-dicarboxylate (2c) as nucleophilic reagent, aromatic $\alpha, \beta$-unsaturated aldehydes $\mathbf{3 a}-\mathbf{g}$ were examined to study the effects of electronic properties and steric hindrance on both enantioselectivity and reactivity. For the substrates 3a, 3b and 3c, bearing substituents of $-\mathrm{NO}_{2}$ and $-\mathrm{CN}$ at the para- or meta-position of the phenyl group, the reactions proceeded smoothly and led to the desired products $4 \mathbf{a}, 4 \mathbf{b}$ and $4 \mathbf{c}$ in $80-86 \%$ yields with $89-92 \%$ ee's (Table 5, entries $1-3)$. With 3d and 3e bearing $-\mathrm{Cl}$ or $-\mathrm{Br}$ substituents at the para-position of the phenyl group as substrates, the desired products $4 \mathbf{d}$ and $4 \mathrm{e}$ were obtained in 61 and $62 \%$ yields with 74 and $77 \%$ ee, respectively (Table 5 , entries 4 and 5). For substrates $\mathbf{3 f}$ and $\mathbf{3 g}$ bearing electron-donating groups (-Me, -OMe) on the phenyl rings, only a trace amount of the desired products could be observed under otherwise identical reaction conditions (Table 5, entries 6 and 7). These experimental results indicated that chemical yields and enantioselectivities were

Table 5: Substrate scope of 2 and 3 catalyzed by chiral amine $1 \mathrm{~m}$
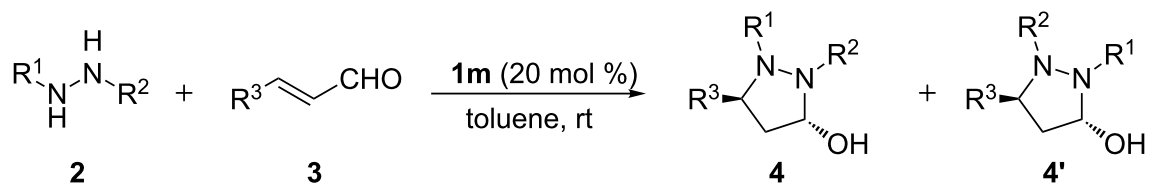

2c: $R^{1}=R^{2}=$ Boc; $2 d: R^{1}=R^{2}=$ COOiPr

2g: $\mathrm{R}^{1}=\mathrm{Boc}, \mathrm{R}^{2}=\mathrm{Ph} ; \mathbf{2} \mathbf{h}: \mathrm{R}^{1}=\mathrm{Boc}, \mathrm{R}^{2}=p-\mathrm{CIPh}$

2i: $\mathrm{R}^{1}=\mathrm{Boc}, \mathrm{R}^{2}=p-\mathrm{BrPh} ; \mathbf{2} \mathbf{j}: \mathrm{R}^{1}=\mathrm{Boc}, \mathrm{R}^{2}=p-\mathrm{MeOPh}$

\begin{tabular}{|c|c|c|c|c|c|c|}
\hline Entry ${ }^{a}$ & Donor & $\mathrm{R}^{3}$ & Time (d) & Yield $(\%)^{b}$ & Ratioc $^{c}$ & ee $(\%)^{d}$ \\
\hline 1 & 2c & $4-\mathrm{NO}_{2} \mathrm{C}_{6} \mathrm{H}_{4}(3 \mathrm{a})$ & 4 & $4 a / 80$ & - & 92 \\
\hline 2 & $2 c$ & $3-\mathrm{NO}_{2} \mathrm{C}_{6} \mathrm{H}_{4}(3 b)$ & 2 & $4 b / 83$ & - & 91 \\
\hline 3 & 2c & $4-\mathrm{CNC}_{6} \mathrm{H}_{4}(3 \mathrm{c})$ & 4 & $4 c / 86$ & - & 89 \\
\hline 4 & 2c & $4-\mathrm{ClC}_{6} \mathrm{H}_{4}(\mathbf{3 d})$ & 4 & $4 d / 61$ & - & 74 \\
\hline 5 & 2c & $4-\mathrm{BrC}_{6} \mathrm{H}_{4}(3 \mathrm{e})$ & 4 & $4 e / 62$ & - & 77 \\
\hline 6 & 2c & $4-\mathrm{MeOC}_{6} \mathrm{H}_{4}(\mathbf{3 f})$ & 4 & $4 f /<5$ & - & - \\
\hline 7 & 2c & $4-\mathrm{MeC}_{6} \mathrm{H}_{4}(\mathbf{3 g})$ & 4 & $\mathbf{4 g} /<5$ & - & - \\
\hline 8 & $2 d$ & $4-\mathrm{NO}_{2} \mathrm{C}_{6} \mathrm{H}_{4}(3 a)$ & 2 & $4 \mathrm{~h} / 60$ & - & 72 \\
\hline 9 & $2 \mathrm{~g}^{\mathrm{e}}$ & $4-\mathrm{NO}_{2} \mathrm{C}_{6} \mathrm{H}_{4}(3 \mathrm{a})$ & 4 & $4 n / 58\left(4 n^{\prime} / 32\right)$ & $1.8: 1$ & $88 / 55$ \\
\hline 10 & $2 h^{e}$ & $3-\mathrm{NO}_{2} \mathrm{C}_{6} \mathrm{H}_{4}(3 b)$ & 4 & $40 / 60$ & $3.2: 1$ & 88 \\
\hline 11 & $2 h^{e}$ & $4-\mathrm{NO}_{2} \mathrm{C}_{6} \mathrm{H}_{4}(3 \mathrm{a})$ & 4 & $4 p / 72$ & $4.5: 1$ & 99 \\
\hline 12 & $2 h^{e}$ & $4-\mathrm{CNC}_{6} \mathrm{H}_{4}(3 \mathrm{c})$ & 4 & $4 q / 65$ & $4.7: 1$ & 93 \\
\hline 13 & $2 h^{\mathrm{e}}$ & $3-\mathrm{CF}_{3} \mathrm{C}_{6} \mathrm{H}_{4}(3 \mathrm{~h})$ & 4 & $4 r / 53$ & $-g$ & 81 \\
\hline 14 & $2 \mathrm{i}^{\mathrm{e}}$ & $4-\mathrm{NO}_{2} \mathrm{C}_{6} \mathrm{H}_{4}(3 \mathrm{a})$ & 4 & $4 s / 74$ & $6.4: 1$ & 99 \\
\hline 15 & $2 \mathbf{i}^{\mathrm{e}}$ & $4-\mathrm{CNC}_{6} \mathrm{H}_{4}(3 \mathrm{c})$ & 4 & $4 t / 72$ & $4.0: 1$ & 90 \\
\hline 16 & $2 \mathrm{j}^{\mathrm{e}}$ & $4-\mathrm{NO}_{2} \mathrm{C}_{6} \mathrm{H}_{4}(3 a)$ & 4 & $4 u^{\prime} / 75$ & $1: 9.0$ & $-/ 11$ \\
\hline 17 & $2 h^{f}$ & $\operatorname{Me}(3 \mathbf{i})$ & 2 & $4 v / 78$ & $>10: 1$ & 72 \\
\hline 18 & $2 i^{f}$ & $\operatorname{Me}(3 \mathbf{i})$ & 2 & $4 w / 83$ & $>10: 1$ & 74 \\
\hline 19 & $2 h^{f}$ & Et $(\mathbf{3} \mathbf{j})$ & 3 & $4 x \mid<10$ & - & - \\
\hline
\end{tabular}

aUnless noted, the reaction was run with $2(0.5 \mathrm{mmol}), 3(0.25 \mathrm{mmol})$, and $1 \mathrm{~m}(0.05 \mathrm{mmol})$ in toluene $(0.5 \mathrm{~mL})$ at room temperature. ${ }^{\mathrm{b}} / \mathrm{solated}$ yield of pure isomer 4 (the data in parentheses is related to the isolated yield of the 4'). 'The ratio based on isolated yield of pure 4 and 4'. 'Determined by HPLC analysis on a chiral stationary phase (Chiralcel OD-H, AD-H or AS-H), $>20: 1 \mathrm{dr}$. ${ }^{\mathrm{e}}$ The ratio of $2 / 3$ is $1.2: 1$. ${ }^{\mathrm{f}}$ The reaction was run with 2 $(0.25 \mathrm{mmol}), 3(0.38 \mathrm{mmol})$, and $1 \mathrm{~m}(0.05 \mathrm{mmol})$ in toluene $(0.5 \mathrm{~mL})$ at room temperature. 'Due to the difficulty of separation of the product $4 \mathbf{r}^{\prime}$ from starting material $\mathbf{2 h}$. 
dramatically affected by the electronic properties and steric hindrance of the aryl group on the $\alpha, \beta$-unsaturated aldehydes. High yield and good enantioselectivity could be obtained with strong electron-withdrawing substituents on the phenyl ring of cinnamaldehydes. When diisopropyl hydrazine-1,2-dicarboxylate (2d) as nucleophilic reagent reacted with 4-nitro cinnamaldehyde (3a), the product $4 \mathrm{~h}$ was obtained in $60 \%$ yield and $72 \%$ ee (Table 5 , entry 8 ). The result showed that the smallsized substituent on hydrazines was unfavorable on the reaction (Table 5 , entry 8 versus entry 1 ). Subsequently, asymmetric disubstituted hydrazines $\mathbf{2} \mathbf{g}-\mathbf{j}$ were investigated for the domino aza-Michael/hemiacetal sequence. Due to nucleophilic competition of the two nitrogens in the asymmetric disubstituted hydrazines, regioselective results were observed for these reactions. For asymmetric disubstituted hydrazines $\mathbf{2 g}$, the reaction gave the 1.8:1 molar ratio of the regioselective products $4 \mathbf{n}$ to 4n'. The major product 4n was obtained in 58\% yield and $88 \%$ ee. The enantioselectivity of the minor product $4 n$ ' was $55 \%$ (Table 5, entry 9). For asymmetric disubstituted hydrazines $\mathbf{2 h}-\mathbf{i}$, the molar ratios of the regioselective products ranged from 3.2:1 to $6.4: 1$. The major products were obtained in moderate to good yields and good enantioselectivities (Table 5, entries $10-15$ ). When disubstituted hydrazine $\mathbf{2} \mathbf{j}$ with an electron-donating group on the aromatic ring was used as the nucleophilic donor, the major, reversely regioselective product $\mathbf{4 u}$ ' was obtained in $75 \%$ yield, but with very low enantioselectivity (11\% ee, Table 5, entry 16$)$. To our delight, $(E)$-but2-enal (3i) was a suitable substrate for this transformation. The reactions of asymmetric disubstituted hydrazines $2 \mathbf{h}$ and $2 \mathbf{i}$ with (E)-but-2-enal (3i) proceeded smoothly and provided the desired products in 78 and $83 \%$ yields with 72 and $74 \%$ ee, respectively (Table 5, entries 17 and 18). However, when the cascade aza-Michael/hemiacetal reaction of $(E)$-pent-2-enal (3j) and $\mathbf{2 h}$ was carried out, only a trace amount of the expected products could be detected (Table 5, entry 19). Fortunately, single crystals of compound $4 \mathrm{~s}$ were obtained by recrystallization from petroleum ether/acetyl acetate, and the absolute configuration was determined by X-ray analyses (Figure 4) [84].

\section{Conclusion}

In summary, we have developed an organocatalytic approach for the synthesis of pyrazolidine derivatives through the cascade aza-Michael/hemiacetal reaction between disubstituted hydrazines and $\alpha, \beta$-unsaturated aldehydes. The asymmetric version of this one-pot cascade reaction has also been realized with $(S)$-diphenylprolinol trimethylsilyl ether $\mathbf{1 m}$ as a secondary amine organocatalyst, and a series of enantiomerically enriched pyrazolidine derivatives were obtained in moderate to good chemical yields with moderate to excellent enantioselectivities. The application of the products and further investigation of the reaction are ongoing in our laboratory.

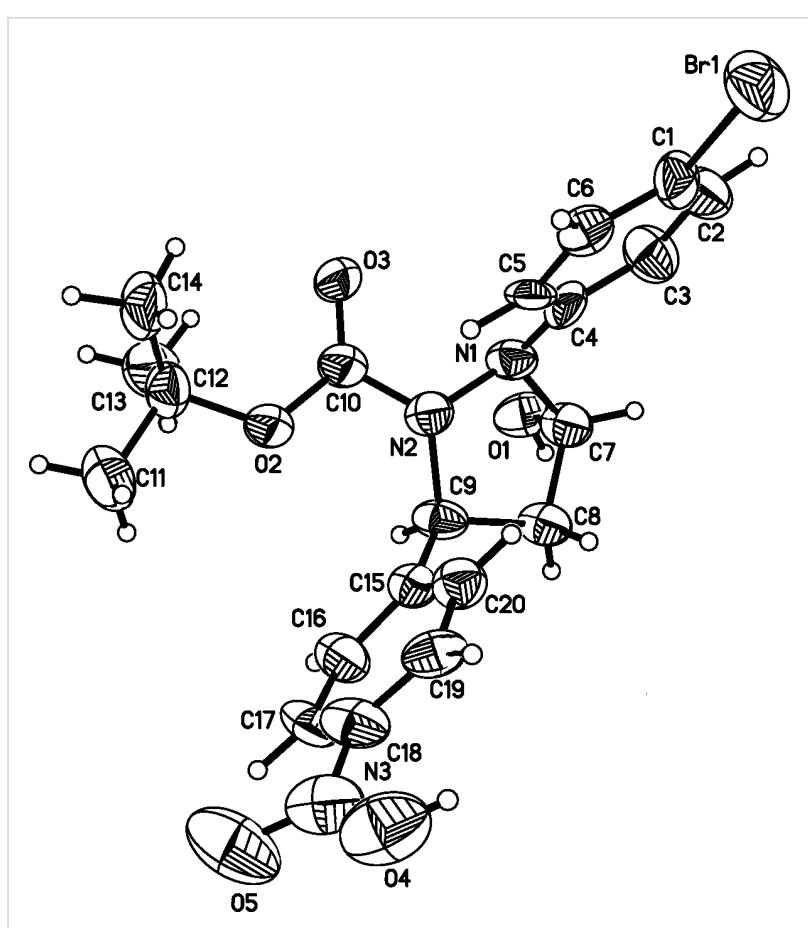

Figure 4: The X-ray crystal structure of chiral compound $4 \mathrm{~s}(40 \%$ thermal ellipsoids).

\section{Experimental}

Representative experimental procedure for the cascade aza-Michael/hemiacetal reaction of disubstituted hydrazines with $\alpha, \beta-$ unsaturated aldehydes

To a stirred solution of catalyst $\mathbf{1 c}$ or $1 \mathbf{m}(20 \mathrm{~mol} \%)$ in $\mathrm{CH}_{2} \mathrm{Cl}_{2}$ or toluene $(0.5 \mathrm{~mL})$ was added $\alpha, \beta$-unsaturated aldehyde 3 ( 1.0 equiv, $0.25 \mathrm{mmol}$ ) and di-substituted hydrazine 2 (1.2 equiv or 2.0 or 5.0 equiv and $0.3 \mathrm{mmol}$ or $0.5 \mathrm{mmol}$ or $1.25 \mathrm{mmol})$ at $\mathrm{rt}$. The reaction was vigorously stirred for 2-5 days. Then, the reaction mixture was directly subjected to flash column chromatography on silica gel (petroleum ether/ ethyl acetate) to afford the corresponding products 4 .

(-)-Di-tert-butyl 3-hydroxy-5-(4-nitrophenyl)pyrazolidine1,2-dicarboxylate (4a): $80 \%$ yield, $>20 / 1 \mathrm{dr}, 92 \%$ ee. The enantiomeric ratio was determined by HPLC on Chiralpak OD-H column (10\% 2-propanol/hexane, $1 \mathrm{~mL} / \mathrm{min}), t_{\text {major }}=$ $7.219 \mathrm{~min}, t_{\text {minor }}=6.013 \mathrm{~min} ;[\alpha]_{\mathrm{D}}{ }^{26}-11.8$ (c 0.38, acetone); ${ }^{1} \mathrm{H}$ NMR $\left(400 \mathrm{MHz}, \mathrm{CDCl}_{3}\right) \delta 8.20(\mathrm{~d}, J=8.6 \mathrm{~Hz}, 2 \mathrm{H}), 7.55(\mathrm{~d}$, $J=8.6 \mathrm{~Hz}, 2 \mathrm{H}), 5.92(\mathrm{~d}, J=4.7 \mathrm{~Hz}, 1 \mathrm{H}), 5.52-5.39(\mathrm{~m}, 1 \mathrm{H})$, $3.40(\mathrm{~s}, 1 \mathrm{H}), 2.71(\mathrm{dd}, J=13.2,8.4 \mathrm{~Hz}, 1 \mathrm{H}), 2.13-2.03(\mathrm{~m}, 1 \mathrm{H})$, $1.53(\mathrm{~s}, 9 \mathrm{H}), 1.43(\mathrm{~s}, 9 \mathrm{H}) ;{ }^{13} \mathrm{C} \mathrm{NMR}\left(100 \mathrm{MHz}, \mathrm{CDCl}_{3}\right) \delta$ $154.27,149.72,147.21,126.75,124.01,82.62,82.56,82.19$, $61.66,43.43,28.33,28.19$; IR (KBr) $v_{\max }: 3354.8,2980.4$, 2934.2, 2854.2, 1728.7, 1705.9, 1600.2, 1518.9, 1456.0, 1367.7, 
1345.9, 1311.6, 1243.1, 1145.0, 990.9, 853.5, $758.4 \mathrm{~cm}^{-1}$; HRMS-ESI $(m / z)$ : $[\mathrm{Na}]^{+}$calcd for $\mathrm{C}_{19} \mathrm{H}_{27} \mathrm{~N}_{3} \mathrm{O}_{7}, 432.1741$; found, 432.1724 .

\section{Supporting Information}

\section{Supporting Information File 1}

General experimental procedures, ${ }^{1} \mathrm{H},{ }^{13} \mathrm{C}$ NMR spectra and HPLC chromatograms for all new compounds, crystal data and structure refinement for enantiopure 4. [http://www.beilstein-journals.org/bjoc/content/ supplementary/1860-5397-8-195-S1.pdf]

\section{Acknowledgements}

We are grateful for financial support from the National Natural Science Foundation of China $(21072145,21272166)$, Foundation for the Author of National Excellent Doctoral Dissertation of PR China (200931), and Natural Science Foundation of Jiangsu Province of China (BK2009115). This project was also funded by the Priority Academic Program Development of Jiangsu Higher Education Institutions (PAPD).

\section{References}

1. Clark, M. P.; Laughlin, S. K.; Laufersweiler, M. J.; Bookland, R. G.; Brugel, T. A.; Golebiowski, A.; Sabat, M. P.; Townes, J. A.; VanRens, J. C.; Djung, J. F.; Natchus, M. G.; De, B.; Hsieh, L. C.; Xu, S. C.; Walter, R. L.; Mekel, M. J.; Heitmeyer, S. A.; Brown, K. K.; Juergens, K.; Taiwo, Y. O.; Janusz, M. J. J. Med. Chem. 2004, 47, 2724-2727. doi:10.1021/jm049968m

2. Kornet, M. J.; Garrett, R. J. J. Pharm. Sci. 1979, 68, 377-388. doi:10.1002/jps.2600680335

3. Tran, K.; Lombardi, P. J.; Leighton, J. L. Org. Lett. 2008, 10, 3165-3167. doi:10.1021/ol8011869

4. Özdemir, Z.; Kandilci, H. B.; Gümüşel, B.; Çaliş, Ü.; Bilgin, A. A. Eur. J. Med. Chem. 2007, 42, 373-379. doi:10.1016/j.ejmech.2006.09.006

5. Jeong, T.-S.; Kim, K. S.; An, S.-J.; Cho, K.-H.; Lee, S.; Lee, W. S. Bioorg. Med. Chem. Lett. 2004, 14, 2715-2717. doi:10.1016/j.bmcl.2004.03.079

6. Yamashita, Y.; Kobayashi, S. J. Am. Chem. Soc. 2004, 126, 11279-11282. doi:10.1021/ja049498I

7. Shirakawa, S.; Lombardi, P. J.; Leighton, J. L. J. Am. Chem. Soc. 2005, 127, 9974-9975. doi:10.1021/ja052307

8. Johnson, M.; Younglove, B.; Lee, L.; LeBlanc, R.; Holt, H., Jr.; Hills, P.; Mackay, H.; Brown, T.; Mooberry, S. L.; Lee, M. Bioorg. Med. Chem. Lett. 2007, 17, 5897-5901. doi:10.1016/j.bmcl.2007.07.105

9. Ali, M. A.; Shaharyar, M. Bioorg. Med. Chem. 2007, 15, 1896-1902. doi:10.1016/j.bmc.2007.01.006

10. Lange, J. H. M.; Kruse, C. G. Curr. Opin. Drug Discovery Dev. 2004, 7, 498-506.

11. Alex, K.; Tillack, A.; Schwarz, N.; Beller, M. Org. Lett. 2008, 10, 2377-2379. doi:10.1021/ol800592s
12. Nair, V.; Biju, A. T.; Mohanan, K.; Suresh, E. Org. Lett. 2006, 8, 2213-2216. doi:10.1021/ol0604623

13. Elguero, J.; Goya, P.; Jagerovic, N.; Silva, A. M. S. In Targets in Heterocyclic Systems; Attanasi, O. A.; Spinelli, D., Eds.; Springer: Berlin, 2003; Vol. 6, p 52.

14. Martín, R.; Rodríguez Rivero, M.; Buchwald, S. L. Angew. Chem., Int. Ed. 2006, 45, 7079-7082. doi:10.1002/anie.200602917

15. Ahmed, M. S. M.; Kobayashi, K.; Mori, A. Org. Lett. 2005, 7, 4487-4489. doi:10.1021/ol051841j

16. Kobayashi, S.; Hirabayashi, R.; Shimizu, H.; Ishitani, H.; Yamashita, Y. Tetrahedron Lett. 2003, 44, 3351-3354. doi:10.1016/S0040-4039(03)00606-3

17. Jäger, V.; Bierer, L.; Dong, H.-Q.; Palmer, A. M.; Shaw, D.; Frey, W. J. Heterocycl. Chem. 2000, 37, 455-465. doi:10.1002/jhet.5570370304

18. Gallos, J. K.; Koumbis, A. E.; Apostolakis, N. E. J. Chem. Soc., Perkin Trans. 1 1997, 2457-2460. doi:10.1039/A704207H

19. Khau, V. V.; Martinelli, M. J. Tetrahedron Lett. 1996, 37, 4323-4326. doi:10.1016/0040-4039(96)00836-2

20. Gergely, J.; Morgan, J. B.; Overman, L. E. J. Org. Chem. 2006, 71, 9144-9152. doi:10.1021/jo061537j

21. Zamfir, A.; Schenker, S.; Bauer, W.; Clark, T.; Tsogoeva, S. B. Eur. J. Org. Chem. 2011, 3706-3709. doi:10.1002/ejoc.201100206

22. Shintani, R.; Fu, G. C. J. Am. Chem. Soc. 2003, 125, 10778-10779. doi:10.1021/ja036922u

23. Kobayashi, S.; Shimizu, H.; Yamashita, Y.; Ishitani, H.; Kobayashi, J. J. Am. Chem. Soc. 2002, 124, 13678-13679. doi:10.1021/ja027681d

24. Chen, W.; Yuan, X.-H.; Li, R.; Du, W.; Wu, Y.; Ding, L.-S.; Chen, Y.-C. Adv. Synth. Catal. 2006, 348, 1818-1822. doi:10.1002/adsc.200606102

25. Chen, W.; Du, W.; Duan, Y.-Z.; Wu, Y.; Yang, S.-Y.; Chen, Y.-C. Angew. Chem., Int. Ed. 2007, 46, 7667-7670. doi:10.1002/anie.200702618

26. Hashimoto, T.; Omote, M.; Maruoka, K. Angew. Chem., Int. Ed. 2011, 50, 3489-3492. doi:10.1002/anie.201100331

27. Hashimoto, T.; Maeda, Y.; Omote, M.; Nakatsu, H.; Maruoka, K. J. Am. Chem. Soc. 2010, 132, 4076-4077. doi:10.1021/ja100787a

28. Ma, S.; Jiao, N.; Zheng, Z.; Ma, Z.; Lu, Z.; Ye, L.; Deng, Y.; Chen, G. Org. Lett. 2004, 6, 2193-2196. doi:10.1021/ol0493498

29. Yang, Q.; Jiang, X.; Ma, S. Chem.-Eur. J. 2007, 13, 9310-9316. doi:10.1002/chem.200700620

30. Shu, W.; Yang, Q.; Jia, G.; Ma, S. Tetrahedron 2008, 64, 11159-11166. doi:10.1016/j.tet.2008.09.049

31. Shu, W.; Ma, S. Chem. Commun. 2009, 6198-6200. doi:10.1039/b912108k

32. LaLonde, R. L.; Wang, Z. J.; Mba, M.; Lackner, A. D.; Toste, F. D. Angew. Chem., Int. Ed. 2010, 49, 598-601. doi:10.1002/anie.200905000

33. Giampietro, N. C.; Wolfe, J. P. J. Am. Chem. Soc. 2008, 130, 12907-12911. doi:10.1021/ja8050487

34. Kotsuki, H.; Ikishima, H.; Okuyama, A. Heterocycles 2008, 75 , 493-529. doi:10.3987/REV-07-620

35. Kotsuki, H.; Ikishima, H.; Okuyama, A. Heterocycles 2008, 75 , 757-797. doi:10.3987/REV-07-621

36. Enders, D.; Narine, A. A. J. Org. Chem. 2008, 73, 7857-7870. doi:10.1021/jo801374j

37. Melchiorre, P.; Marigo, M.; Carlone, A.; Bartoli, G. Angew. Chem., Int. Ed. 2008, 47, 6138-6171. doi:10.1002/anie.200705523 
38. Bertelsen, S.; Jørgensen, K. A. Chem. Soc. Rev. 2009, 38, 2178-2189. doi:10.1039/b903816g

39. Bella, M.; Gasperi, T. Synthesis 2009, 1583-1614. doi:10.1055/s-0029-1216796

40. Enders, D.; Wang, C.; Liebich, J. X. Chem.-Eur. J. 2009, 15, 11058-11076. doi:10.1002/chem.200902236

41. Mukherjee, S.; Yang, J. W.; Hoffmann, S.; List, B. Chem. Rev. 2007, 107, 5471-5569. doi:10.1021/cr0684016

42. Erkkilä, A.; Majander, I.; Pihko, P. M. Chem. Rev. 2007, 107, 5416-5470. doi:10.1021/cr068388p

43. Doyle, A. G.; Jacobsen, E. N. Chem. Rev. 2007, 107, 5713-5743. doi:10.1021/cr068373r

44. Moyano, A.; Rios, R. Chem. Rev. 2011, 111, 4703-4832. doi:10.1021/cr100348t

45. Enders, D.; Grondal, C.; Hüttl, M. R. M. Angew. Chem., Int. Ed. 2007, 46, 1570-1581. doi:10.1002/anie.200603129

46. Yu, X.; Wang, W. Org. Biomol. Chem. 2008, 6, 2037-2046. doi:10.1039/b800245m

47. Grondal, C.; Jeanty, M.; Enders, D. Nat. Chem. 2010, 2, 167-178. doi:10.1038/nchem.539

48. Itoh, T.; Yokoya, M.; Miyauchi, K.; Nagata, K.; Ohsawa, A. Org. Lett. 2003, 5, 4301-4304. doi:10.1021/ol030103x

49. Yamamoto, Y.; Momiyama, N.; Yamamoto, H. J. Am. Chem. Soc. 2004, 126, 5962-5963. doi:10.1021/ja049741g

50. Sundén, H.; Ibrahem, I.; Eriksson, L.; Córdova, A. Angew. Chem., Int. Ed. 2005, 44, 4877-4880. doi:10.1002/anie.200500811

51. Itoh, T.; Yokoya, M.; Miyauchi, K.; Nagata, K.; Ohsawa, A. Org. Lett. 2006, 8, 1533-1535. doi:10.1021/ol0530575

52. Ibrahem, I.; Rios, R.; Vesely, J.; Zhao, G.-L.; Córdova, A. Chem. Commun. 2007, 849-851. doi:10.1039/b613410f

53. Sundén, H.; Rios, R.; Ibrahem, I.; Zhao, G.-L.; Eriksson, L.; Córdova, A. Adv. Synth. Catal. 2007, 349, 827-832. doi:10.1002/adsc.200600513

54. Vesely, J.; Ibrahem, I.; Zhao, G.-L.; Rios, R.; Córdova, A. Angew. Chem., Int. Ed. 2007, 46, 778-781. doi:10.1002/anie.200603810

55. Rueping, M.; Azap, C. Angew. Chem., Int. Ed. 2006, 45, 7832-7835. doi:10.1002/anie.200603199

56. Li, H.; Wang, J.; Xie, H.; Zu, L.; Jiang, W.; Duesler, E. N.; Wang, W. Org. Lett. 2007, 9, 965-968. doi:10.1021/ol062877u

57. Li, H.; Zu, L.; Xie, H.; Wang, J.; Wang, W. Chem. Commun. 2008, 5636-5638. doi:10.1039/b812464g

58. Pesciaioli, F.; Vincentiis, F. D.; Galzerano, F.; Bencivenni, G.; Bartoli, G.; Mazzanti, A.; Melchiorre, P. Angew. Chem., Int. Ed. 2008, 47, 8703-8706. doi:10.1002/anie.200803647

59. Lu, M.; Zhu, D.; Lu, Y.; Hou, Y.; Tan, B.; Zhong, G. Angew. Chem., Int. Ed. 2008, 47, 10187-10191. doi:10.1002/anie.200803731

60. Zhu, D.; Lu, M.; Chua, P. J.; Tan, B.; Wang, F.; Yang, X.; Zhong, G. Org. Lett. 2008, 10, 4585-4588. doi:10.1021/ol801864c

61. Yang, H.; Carter, R. G. J. Org. Chem. 2009, 74, 5151-5156. doi:10.1021/jo9009062

62. Wang, Y.-F.; Zhang, W.; Luo, S.-P.; Li, B.-L.; Xia, A.-B.; Zhong, A.-G.; Xu, D.-Q. Chem.-Asian J. 2009, 4, 1834-1838. doi:10.1002/asia.200900298

63. Hong, L.; Sun, W.; Liu, C.; Wang, L.; Wang, R. Chem.-Eur. J. 2010, 16, 440-444. doi:10.1002/chem.200902638

64. He, Z.-Q.; Zhou, Q.; Wu, L.; Chen, Y.-C. Adv. Synth. Catal. 2010, 352, 1904-1908. doi:10.1002/adsc.201000291
65. Takizawa, S.; Inoue, N.; Hirata, S.; Sasai, H. Angew. Chem., Int. Ed. 2010, 49, 9725-9729. doi:10.1002/anie.201004547

66. Enders, D.; Göddertz, D. P.; Beceño, C.; Raabe, G. Adv. Synth. Catal. 2010, 352, 2863-2868. doi:10.1002/adsc.201000658

67. Deiana, L.; Zhao, G.-L.; Lin, S.; Dziedzic, P.; Zhang, Q.; Leijonmarck, H.; Córdova, A. Adv. Synth. Catal. 2010, 352, 3201-3207. doi:10.1002/adsc.201000650

68. Enders, D.; Wang, C.; Raabe, G. Synthesis 2009, 4119-4124. doi:10.1055/s-0029-1217069

69. Enders, D.; Wang, C.; Yang, X.; Raabe, G. Synlett 2011, 469-472. doi:10.1055/s-0030-1259326

70. Müller, S.; List, B. Angew. Chem., Int. Ed. 2009, 48, 9975-9978. doi:10.1002/anie.200905035

71. Mahé, O.; Dez, I.; Levacher, V.; Brière, J.-F. Angew. Chem., Int. Ed. 2010, 49, 7072-7075. doi:10.1002/anie.201002485

72. Sinkkonen, J.; Ovcharenko, V.; Zelenin, K. N.; Bezhan, I. P.; Chakchir, B. A.; Al-Assar, F.; Pihlaja, K. Eur. J. Org. Chem. 2002, 3447-3454. doi:10.1002/1099-0690(200210)2002:20<3447::AID-EJOC3447>3.0.C O;2-L

73. Fernández, M.; Vicario, J. L.; Reyes, E.; Carrillo, L.; Badía, D. Chem. Commun. 2012, 48, 2092-2094. doi:10.1039/C2CC17370K

74. Perdicchia, D.; Jørgensen, K. A. J. Org. Chem. 2007, 72, 3565-3568. doi:10.1021/jo0626717

75. Campbell, N. R.; Sun, B.; Singh, R. P.; Deng, L. Adv. Synth. Catal. 2011, 353, 3123-3128. doi:10.1002/adsc.201100447

76. Fernández, M.; Reyes, E.; Vicario, J. L.; Badía, D.; Carrillo, L. Adv. Synth. Catal. 2012, 354, 371-376. doi:10.1002/adsc.201100722

77. Jensen, K. L.; Dickmeiss, G.; Jiang, H.; Albrecht, Ł.; Jørgensen, K. A. Acc. Chem. Res. 2012, 45, 248-264. doi:10.1021/ar200149w

78. Xu, L.-W.; Li, L.; Shi, Z.-H. Adv. Synth. Catal. 2010, 352, 243-279. doi:10.1002/adsc.200900797

79. Mielgo, A.; Palomo, C. Chem.-Asian J. 2008, 3, 922-948. doi:10.1002/asia.200700417

80. Brandau, S.; Maerten, E.; Jørgensen, K. A. J. Am. Chem. Soc. 2006, 128, 14986-14991. doi:10.1021/ja065507+

81. Jiang, H.; Nielsen, J. B.; Nielsen, M.; Jørgensen, K. A. Chem.-Eur. J. 2007, 13, 9068-9075. doi:10.1002/chem.200700696

82. Wang, Y.; Li, P.; Liang, X.; Zhang, T. Y.; Ye, J. Chem. Commun. 2008, 1232-1234. doi:10.1039/b717000a

83. Marqués-López, E.; Herrera, R. P. Curr. Org. Chem. 2011, 15, 2311-2327.

84. CCDC 854579 (4a), CCDC 854580 (4n) and CCDC 860007 (4s) contain the supplementary crystallographic data for this paper. These data can be obtained free of charge from The Cambridge Crystallographic Data Centre via http://www.ccdc.cam.ac.uk/data_request/cif. 


\section{License and Terms}

This is an Open Access article under the terms of the Creative Commons Attribution License

(http://creativecommons.org/licenses/by/2.0), which permits unrestricted use, distribution, and reproduction in any medium, provided the original work is properly cited.

The license is subject to the Beilstein Journal of Organic Chemistry terms and conditions:

(http://www.beilstein-journals.org/bjoc)

The definitive version of this article is the electronic one which can be found at:

doi:10.3762/bjoc.8.195 